\title{
Rotator Cuff Repair Augmentation Using Osteoinductive Growth Factors
}

\author{
Rhea S. Menon ${ }^{1} \cdot$ Nicholas M. Wragg ${ }^{2} \cdot$ Samantha L. Wilson $^{2}$ (B)
}

Accepted: 8 January 2019 / Published online: 18 January 2019

(C) The Author(s) 2019

\begin{abstract}
Rotator cuff injuries (RCIs) present a major health problem due to high incidences of degenerative tears greater than $3 \mathrm{~cm}$ and prevalence of re-tears following surgical procedures. Since healing and functional restoration relies upon bone ingrowth into the tendon, it is hypothesised that sustained delivery of osteoinductive factors including bone morphogenetic proteins (BMPs), specifically BMP2-7, may significantly improve RCI tendon-bone healing. Here, growth factor candidates and delivery mechanisms are reviewed, specifically for improved RCI healing through enhanced bone ingrowth. In addition to BMPs, other potentially osteogenic factors including platelet-derived growth factors (PDGF), fibroblast growth factor (FGF), transforming growth beta isoforms (TGF- $\beta 1$ and TGF-3) and parathyroid hormone (PTH) are evaluated since they can induce bone formation at the healing tendon attachment site. Several challenges must be addressed prior to clinical translation. The majority of published studies utilise in vivo animal models. In general, BMP-7 demonstrates a stronger stimulating effect when compared to BMP-2; the reported effectiveness of BMP-2 is often conflicting. Alternative factors, including PDGF and PTH, also demonstrate potential for assisting bone growth in enthesis healing. The use of sustained and biomimetic delivery systems appears to have the greatest positive effects. Some studies have demonstrated a dose-dependent effect, in conjunction with varying age, indicating that stratified therapies could be a viable solution for RCI healing. To adequately resolve potential treatments for RCI, further expanded and correlated animal trials must be undertaken, and indicative human trials are required with consideration of surgical and patient-specific influences.
\end{abstract}

Keywords Rotator cuff · Osteoinductive $\cdot$ Bone morphogenetic proteins $\cdot$ Growth factors $\cdot$ Enthesis healing

\section{Introduction}

Rotator cuff tears are a highly prevalent musculoskeletal injury (Fig. 1); more than 200,000 repair procedures are performed annually in the USA alone, resulting in an estimated $\$ 474$ million in health care costs [1]. Furthermore, there is a high prevalence of structural failures post repair, with surgically repaired tendons prone to a high rate of re-tear (between 20 and 95\%) [1]. It is known that rotator cuff healing occurs in

This article is part of the Topical Collection on Medicine

Samantha L. Wilson

s.wilson2@lboro.ac.uk

1 National Centre for Sport and Exercise Medicine, School of Sport, Exercise and Health Sciences, Loughborough University, Epinal Way, Loughborough, Leicestershire LE11 3TU, UK

2 Centre for Biological Engineering, Wolfson School of Mechanical, Electrical and Manufacturing Engineering, Loughborough University, Epinal Way, Loughborough, Leicestershire LE11 3TU, UK
3 stages: inflammation, repair, and remodelling. Upon completion of the healing process, the normal rotator cuff enthesis (osteotendinous unit) fails to regenerate [2]. Following repair, rotator cuff tendon healing is often limited by a deficit in tissue formation, with gap formation at the repair site being a common occurrence. Hence, the tendon is weaker than the native insertion site, which renders repairs prone to failure and, thus, repeat injuries [3].

A review of experimental studies by Gulotta and Rodeo (2009) established that bone ingrowth is vital to the healing of the repaired rotator cuff tendon and bone [3]. With this in mind, it has been hypothesised that the administration of osteoinductive agents could improve the healing of a tendon attached to the bone surface and thus strengthen the repair [3]. As a result, there have been a number of studies aimed at analysing the use of osteoinductive factors including bone morphogenetic proteins, e.g. BMP-2 through 7; for rotator cuff enthesis healing [1]. Promising results using osteoinductive factors to improve tendon healing have been reported both in vitro and in vivo, although the majority of studies are reliant upon the use of animal models [4]. However, peer-reviewed 
reports, which evaluate osteoinductive growth factors specifically for rotator cuff injuries, remain limited [5-10]; and there has yet to be a study that evaluates the effectiveness of growth factors in the treatment of rotator cuff injuries (RCIs) in humans [11].

Within the existing literature, it has become apparent that multiple factors play a role when attempting to optimise the dosage of growth factors for therapeutic applications. Determining the most effective factor or combination of factors, the optimum dose, timing, and vehicle for delivery, whilst maintaining their localisation and intended bioactivity at the injury site, is a requisite [1]. When assessing whether an intervention is successful in impacting healing in RCI, the effects of surgery and general condition of the patient, animal or human, is an important consideration. Potential factors which can affect healing have been extensively studied and reviewed [12-14] and should be listed in any report to enable true comparisons between studies (Table 1).

Identifying the most appropriate preclinical model to evaluate the strategy is also necessary as no single animal model is capable of reproducing all of the features of the human injury, and hence, this review aims to compare the current strategies that have used osteoinductive growth factors specifically for injuries of the rotator cuff, with some inference from the similar anterior cruciate ligament (ACL), to identify the most promising methods for biological augmentation. BMPs $12-$ 14, also known as growth differentiation factors (GDFs) 5-7 are distinct from the osteoinductive BMPs (BMP-2, BMP-4, BMP-7) in the sense that they promote tendon and fibrocartilage formation [3] and not bone and, hence, will not be evaluated in this review.

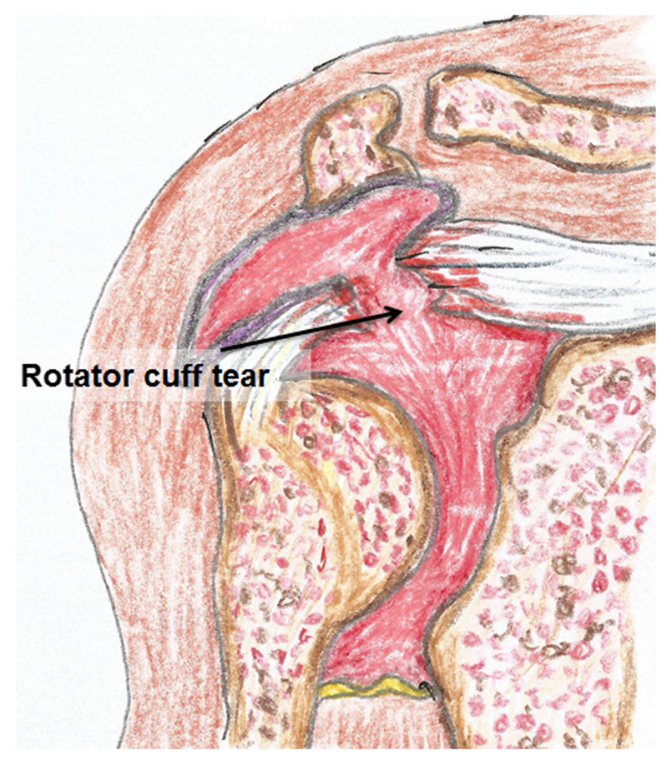

Fig. 1 Rotator cuff tear and gap formation

\section{Comparison of Delivery Vehicles for Growth Factor Therapies}

Due to their short half-life, and a low specificity in vivo [85] determining how to regulate growth factor activity is vital when developing therapeutic treatments. There are several methods that have been investigated both in vivo and in vitro with the specific aim of promoting a sustained, localised release of growth factors at the injury site.

\section{In Vivo Models}

In an early study by Rodeo (2007), an "osteoinductive bone marrow protein extract" comprised of proteins BMP-2 through 7, transforming growth factor beta 1 to 3 (TGF- $\beta 1-$ 3 ), and basic fibroblast growth factor (b-FGF) were delivered as a growth factor mixture via a collagen sponge, in an ovine infraspinatus tendon detachment model [5]. Rodeo hypothesised that this could improve the healing of a tendon attached to the bone surface as it would induce greater bone ingrowth [5]. New bone and soft tissue formation were analysed via radiographs, magnetic resonance imaging (MRI), and histological analysis at 6 and 12 weeks. In comparison to the control groups, the specimens that had received growth factor treatment demonstrated significantly higher levels of new bone formation (not present in controls) and newly formed soft tissue in the tendon-bone gap. Tensile testing revealed that the ultimate load-to-failure was significantly greater following growth factor treatment, when compared to collagen implants alone at 6 weeks [5]. However, these failure loads were only approximately $31 \%$ of the normal tendon strength; this could be due to the disorganised reparative matrix resulting in inferior biomechanical properties. Furthermore, the authors postulated that the collagen sponge implant may have elicited a subtle immune response that was detrimental to new tissue formation. This highlights the importance of the appropriate selection and need to understand the kinetics of the delivery scaffold.

In a following study, Kovacevic and Rodeo (2008) discuss two sheep model studies, observing the effect of mixed fibroblast growth factor (FGF) and BMP-2 through 7 and BMP-12 in various delivery vehicles. Akin to the previously reported studies in ovine models (suture through bone tunnel), it was observed that scar tissue formed within the gap between tendon and bone; however, the mixture created a more robust fibrocartilaginous zone in comparison to controls. Intervention with BMP-12 resulted in increased load-tofailure ratios and stiffness (up to three times greater) after 8 weeks. From histological evaluation of the groups, reestablishment of the collagen fibre continuity between the bone and enthesis scar tissue was observed. Increased content of glycosaminoglycans (GAGs) was also present suggesting fibrocartilage formation [86]. 
Table 1 Factors which affect healing of rotator cuff healing

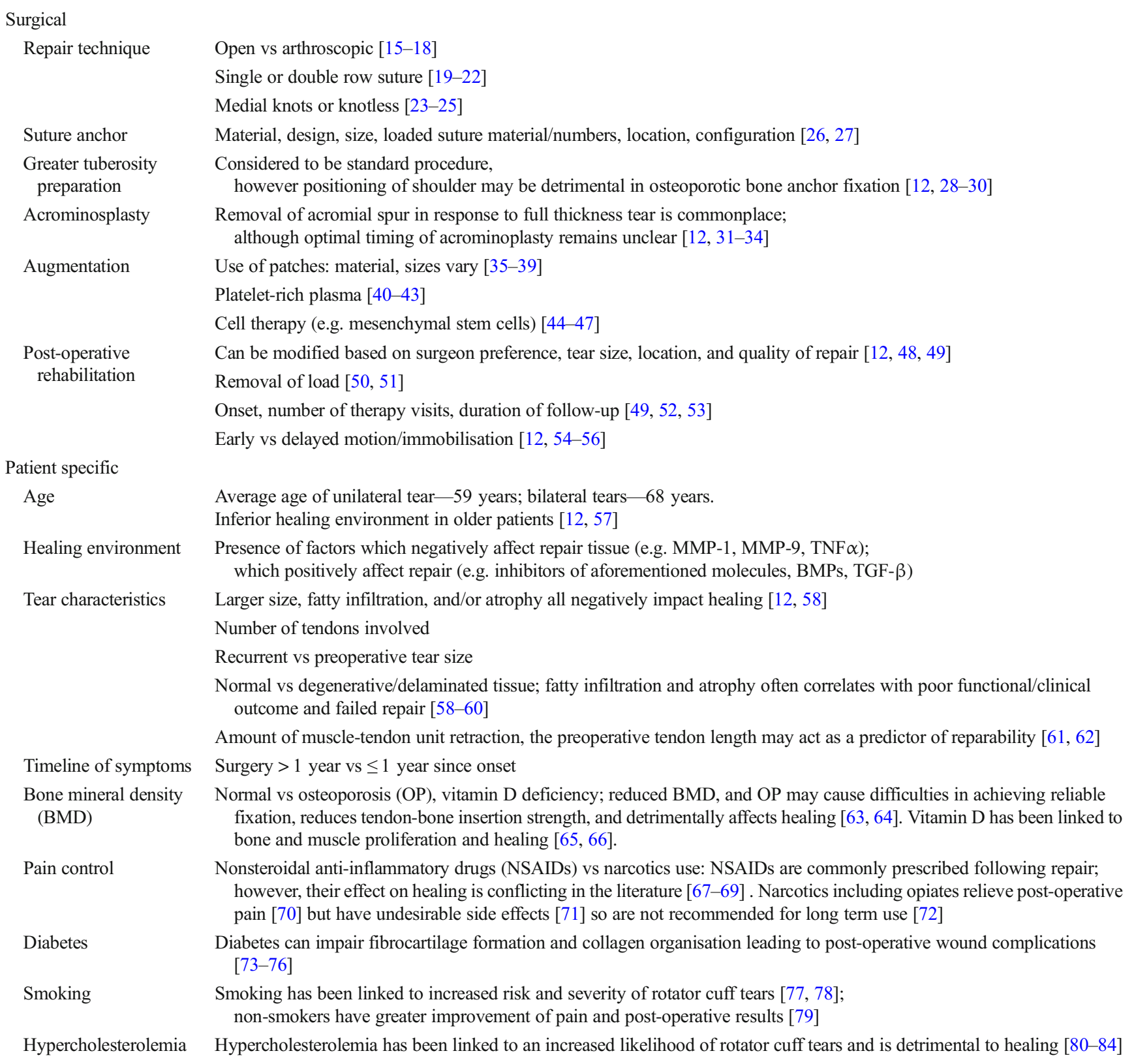

As an isolated component, BMP-7 has been reported to induce cell differentiation into chondrocytes and stimulate cartilage matrix production when delivered to the shoulder joint of rats [8]. It was hypothesised that the use of a crosslinked gelatine hydrogel sheet (GHS) would maintain a sustained release and localised concentration of BMP-7, thus promoting rotator cuff repair. In comparison to controls, whereby BMP-7 was administered to the subacromial bursa via injection, GHS impregnated with BMP-7 and implanted onto tendon demonstrated significantly improved enthesis matrix production and, as a result, improved tendon-to-bone maturation scores and biomechanical properties [8]. Thus, the use of gelatine hydrogels, which are approved for clinical applications, provide an economical, customisable scaffold for the sustained release of BMP-7 for up to several weeks and a viable solution for RCI repair.

In addition to the use of hydrogel scaffolds, the use of biological patches has been investigated as an alternative delivery solution, particularly for large tears and rotator cuff repairs that have been deemed "irreparable" [87]. Lee et al. (2016) first reported the use of a dermal patch isolated from a human cadaver, to deliver BMP-2 [10]. In the study, a rhBMP2-coated dermal patch $(1 \mathrm{~cm} \times 2 \mathrm{~cm})$ was inserted in a leporine model of chronic RCI. The purpose was to evaluate the 
effectiveness of the healing-inductive capacity of the biological patch. The results demonstrated that the inserted rhBMP2-coated acellular dermal patch significantly improved new bone formation and enhanced biomechanical properties including ultimate tensile strength [10]. Although there are numerous materials available for biological patches including dermal matrices, xenogeneic intestinal submucosa or pericardium, and ceramic- or polymer-based synthetics available [88, 89], the biomechanical properties of cadaveric acellular dermal matrices appear to be a better option; potentially due to the maintenance and continuity of the inherent collagen structure. However, irrespective of the delivery mechanism or material, caution must be used with the sustained delivery of highdosage BMPs, since BMP-7, and more frequently BMP-2, is often associated with complications including overabundant bone growth and heterotrophic ossification (HO) [35-37, 90, 91] when used to treat musculoskeletal disorders.

In developmental biology, Indian Hedgehog (Ihh) and parathyroid hormone (PTH)-related peptide (PTHrP) exist as reciprocal mediators in a feedback loop to control both chondrogenesis and mineralisation of the growth plate and enthesis $[38,39]$. Taking cues from this, Hettrich et al. (2012) injected 114 Sprague-Dawley rats subcutaneously with $10 \mu \mathrm{g} / \mathrm{kg}$ of rhPTH on the day of surgery. From this, increased mineral content, bone volume, fibrocartilage, osteoblast presence, and blood vessels, as well as more favourable collagen fibre organisation, was observed after 56 days. Despite this, the biomechanical properties of the interface did not improve, suggesting either greater integration is needed or additional stimuli to enhance these properties [92]. A follow-up study by Duchman et al. (2016), utilising the same dosage and model in 108 rats, delayed the start of rhPTH injection until day 7 post-surgery to avoid the inflammatory phase. Two weeks postoperatively, treated rats demonstrated significantly greater load-to-failure than controls, although at 16 weeks, no significant differences were found [93].

\section{In Vitro Models}

Pauly (2012) aimed to investigate whether BMP-2 and BMP7 could positively affect human RC tenocytes in vitro [6]. The tenocyte-like cells (TLCs) isolated from human supraspinatus and the long head of the biceps were isolated and incubated with the growth factors, alone and in combination. BMP-7 stimulated TLC activity, expression and production of collagen-I, in a dose-dependent manner. BMP-2 also stimulated collagen-I production in TLCs; however, cell activity decreased with higher dosages. The combination of BMP-2 and BMP-7 reduced all parameters in comparison to BMP-7 alone.

Klatte-Schultz (2013) postulated that inferior biological characteristics of TLCs may contribute to diminished rotator cuff healing [7]. In their study, the stimulation potential of human supraspinatus TLCs was investigated. Cell count, collagen-I expression, and protein synthesis, which are significant factors for the tendon-bone healing of the rotator cuff, were all stimulated following the application of BMP-2 and BMP-7 in 3D culture.

\section{Critique of Growth Factor Therapies for Rotator Cuff Repair}

\section{In Vivo Strategies}

Despite in vivo studies, tendon repair studies by Rodeo (2007) demonstrate that the use of a collagen sponge to deliver osteoinductive factors had the greatest biomechanical strength in comparison to the controls; it was observed that this technique consistently detached from the repair site with the gap only becoming evident following MRI analysis [5]. This is an important discovery since other investigators are using the same model for evaluation [86, 94-96]. Although they were unable to study healing of an intact tendon, the resultant model of tendon-bone gap healing is clinically relevant due to the reported high rate of gap formation between tendon-bone [97].

There are limitations to the animal model used in Rodeo's study, as the bone-forming potential of sheep is far greater than that in humans. Another limitation is that the healing of an acute repair was examined, which does not mimic the typical clinical situation. They also had a relatively small sample size, resulting in low power for clinical comparisons.

Despite the initial positive outcome from the later sheep model studies which utilised a mixture of fibroblast growth factor (FGF) and BMP-2 through 7, and BMP-12; it was suggested by Kovacevic and Rodeo (2008) that, following normalisation of failure loads to tissue volume, that the enhanced formation of fibrocartilage was actually poor-quality scar tissue rather than true regeneration.

Kabuto et al (2015) used GHS, which allows for the preservation of the biological activity of BMP-7 [8]. The different methods of growth factor application (injection vs. GHS implant) demonstrated the efficacy of delivery when comparing the GHS implant to local injection. This study also took into consideration the lengthy process of rotator cuff healing; hence, administered BMP-7 must exert a sustained effect. The GHS is a good option, as its safety is approved for clinical use and it is economically produced.

The sustained release of BMP-7 due to the GHS favourable collagen fibre orientation corresponds to the findings by Pauly (2012). The results also suggest that the GHS acted not only in the sustained release of growth factors but also by itself in tissue repair, similar to the collagen sponge in Rodeo's (2007) study. It is worth noting that Kabuto et al. did not observe any evidence of $\mathrm{HO}$ through microcomputed tomography $(\mu \mathrm{CT})$ analysis. The sustained release at a reduced 
dosage of BMP-7 may have reduced risk of formation, which has been reported previously as local concentrations of BMP7 increase [36]. Kabuto et al. do, however, describe the limitations of the study in which the specific anatomy of the murine model differs from the human shoulder. Additionally, retear in rats has not been observed postoperatively, and as in the previous model, it does not reflect degenerative tear as in humans [50]. Despite this, the murine model is sufficiently similar enough to continue to be used in in vivo studies [98].

The work by Lee (2017) is the first study to evaluate effects of an acellular dermal patch combined with BMP-2 [10]. A chronic RCI model was used, which, in comparison to other published literature, is more representative of clinical injury. Acellular dermal matrix has shown much better mechanical support than any other ECM-based scaffolds [2]. However, the biodegradation of the GHS must be investigated further to optimise the healing and biomechanical outcomes.

Although rhBMP-2 has proven promising for tendon-bone healing, many limitations still remain for the clinical application based on safety and effectiveness; with conflicting evidence from a previous study on stromal cells which showed that rhBMP-2 led to impaired tendon-bone healing [9]. The study was also limited in that it did not demonstrate the effectiveness of various doses of rhBMP-2.

Hettrich et al. (2012) and Duchman (2016) investigated the use of Ihh and PTHrP in rats. Both these studies used a dosage based on previous literature, in which doses based in a range that may be tolerated by humans were found to be effective in enhancing fracture healing [99]. Although further optimisation of the timeline and dosage is obviously required, PTH represents a feasible augmentation to current surgical interventions in the treatment of rotator cuff repair.

\section{In Vitro Strategies}

Pauly (2012) evaluated the effect of BMP-2 and BMP-7 on human TLCs in vitro [6], unlike the aforementioned studies which only used animal models. As it compared both growth factors alone, it helped denote that overall, application of BMP-7 led to better results than with BMP-2. It also demonstrated that, the combined application of both showed decreased parameters when compared with BMP-7 alone; suggesting that BMP-2 could possibly exert a negative influence on the expression of BMP-7. Reports in this regard are conflicting; Tsai (2003) found a reduction in BMP-2 expression by $40 \%$ under BMP-7 exposure [100]. On the contrary, Nicklin (2000) reported upregulated BMP-2 expression after BMP-7 exposure [101]. One possible explanation could be that BMP-2 and BMP-7 partially bind to the same receptors, and this could have led to competitive binding [6]. Pauly also studied dose-dependent effects and found a maximum effect for BMP-7 at dosages of $1000 \mathrm{ng} / \mathrm{mL}$. This finding is in contrast to Yeh and Tsai (2008) who observed declining effects beyond $100 \mathrm{ng} / \mathrm{mL}$ [102]. Differences in these studies could be due to different cell origin, i.e. not rotator cuff, and/or culture conditions. However, since the donor material was obtained from torn rotator cuff cells, the study is more clinically appropriate in comparison to using intact tendon.

One of the limitations of the previous study was that no TLC characteristics for sub-groups were studied, which was later investigated by Klatte-Schultz (2013), on TLCs from rotator cuff of female donors [7]. Their findings correspond to those with Pauly (2012), of a stronger stimulating effect with BMP-7 than with BMP-2 [6]. Most importantly, the results were age-specific and indicated that possibly a higher dosage of growth factors would be needed in older female donors. This study, therefore, aimed to develop more patient-specific therapy compared to uniform treatment of rotator cuff tears. However, the study failed to link female sex to inferior cuff healing; this could be due to the in vitro environment, which cannot mimic the role hormones play in the body.

Overall, BMP-7 has demonstrated a stronger stimulating effect than BMP-2, which has been agreed upon by the majority of published studies. On the contrary, the effectiveness of BMP2 has remarkable conflicting evidence, with some studies suggesting reduction $[6,100]$ and some, reporting upregulation of BMP-2 with exposure to BMP-7 in ACL repair (ACL), which has very similar injury and repair mechanisms to RCI [101]. Lipner's (2015) study makes a counter-argument stating that rhBMP-2 led to impaired healing, but it can be argued that BMP-2 in their study was delivered using a gene delivery approach, leading to a sustained, but uncontrolled dosage [9]. It is possible that a different dose of BMP-2 may have been more effective in improving tendon-to-bone healing. The study by Pauly (2012) can be considered as the most demonstrative as not only did they compare the growth factors in combination as well as alone but also studied dose-dependent effect and used a clinically relevant repair model. [6]

\section{Alternative Growth Factors to Induce Osteogenesis}

Whilst not traditionally used as an osteoinductive factor, platelet-derived growth factor (PDGF) is a possible factor for future consideration. It has also been shown to inhibit osteoinduction and chondrogenesis, from demineralized bone matrix in skeletal muscle [103], but equally, in combination with BMP-2, it significantly increased osteogenic differentiation. This was demonstrated in an in vitro model of skeletal muscle [104] suggesting potential for use in other soft tissues. In addition, PDGF has been shown in vivo to increase bone formation and supplement fracture healing [105-107]. Furthermore, Caplan (2011) poses that PDGF-BB is critical for osteogenesis, in that it has been shown to free pericytes from their position, allowing an influx of mesenchymal stem cells (MSCs) to that location and facilitating vascular reorganisation and replenishment of osteoblasts following 
their natural expiry during bone formation [108]. The use of PDGF to enhance bone ingrowth in tendon reattachment has yet to be studied in vivo with most studies focusing on the role of PDGF in matrix production in the tendon aspect of surgical repair [38, 109-111]. FGFs have also been implicated in bone regeneration, despite a general association with fibroblastic tissues, such as tendons. FGFs are important signalling molecules which regulate endochondral ossification and are featured heavily in fracture healing [112]. Similar to PDGF, the application of FGF, specifically FGF-2 $(3 \mu \mathrm{g}$ and $30 \mu \mathrm{g})$, reportedly increases the formation of dense tendon-like tissue in a rabbit model, with ectopic calcification apparent via microcomputed tomography [113]. As demonstrated above, the method of delivery is an important consideration in any healing intervention, more so when utilising a molecule which is not inherently osteoinductive.

Kim et al. (2011) investigated the use of TGF- $\beta 1$ and TGF- $\beta 3$ and the enthesis of a repaired rat supraspinatus tendon. Utilising an osmotic pump delivery system, Kim et al. observed an increase in type-III collagen, when compared to controls, indicative of scar-mediated healing [114]. The TGF- $\beta 3$ group demonstrated no differences with paired controls; however, in a following study utilising a heparin-/fibrinbased vehicle, accelerated healing with associated cell mechanisms was observed, specifically associated with soft tissue healing [115]. In contrast, Kovacevic et al. (2011) utilised a calcium-phosphate (Ca-P) matrix to deliver $2.75 \mu \mathrm{g}$ of TGF- $\beta 3$ [116] into the supraspinatus tendon of male Sprague-Dawley rats. In groups with just Ca-P intervention, new bone, increased fibrocartilage, and matrix organisation were observed. With the addition of the TGF- $\beta 3$ to the Ca$\mathrm{P}$, the strength of the tendon-bone interface was significantly improved (4 weeks after intervention) and a more favourable collagen type-I/type-III ratio, indicative of a more mature stage of healing.

A peptide consisting of 13 amino acids called Sadat-Habdan mesenchymal stimulating peptide (SHMSP) was investigated for use in ACL reconstruction [117] to enhance bone anchorage. Utilising 20 skeletally mature rabbits, 10 had an intervention of SHMSP and the remaining 10 rabbits received only a bone tunnel repair. In comparison to the control, the SHMP group showed bone formation from 4 weeks with extensive new bone growth in the tunnel by week 8 . Whilst this indicates the potential for enhanced bone-tendon healing, further work is obviously required to confirm this result and is acknowledged in the discussion of the report [117].

\section{Conclusion}

From existing research, it can be concluded that BMP-7 has demonstrated the most effectiveness amongst the BMP osteoinductive growth factors, when used alone rather than in combination, with a maximum effect for BMP-7 dosage of $1000 \mathrm{ng} / \mathrm{mL}$. Use of sustained delivery systems including GHSs and acellular matrices seem to be imperative in promoting healing as BMPs have short half-lives and require a delivery system that can maintain their effects continuously, since this is not always feasible when using local injections or systemic modes of delivery. Acellular dermal matrix grafts not only have higher suture pull-out strength in comparison to other extracellular matrix scaffolds but also minimise the problems associated with graft rejection. Studies have also explored the use of factors that are not classically associated with osteoinduction. PDGF, FGF, and TGF- $\beta$ isoforms, although sometimes associated with properties detrimental to RCI healing, such as fibrosis and scarring, have shown promising results when used in combination or in place of BMPs. However, the delivery method must be carefully considered, and larger in vivo studies are still required.

A chronic injury model seems most appropriate for research, with higher relevance when human tenocytes are incorporated when compared to animal models alone. For the future outlook, growth factor delivery systems must be designed to provide an active cell-instructive environment during the therapeutic healing period. Such a strategy would especially benefit the geriatric population whose healing mechanism is detrimentally affected by senescence and degeneration.

Developmental studies using PTHrh have highlighted the importance of optimising the timing of the delivery of healing factors, especially regarding inflammatory healing responses. Further, there is a need for prolonged, in-depth analysis of the structure and organisation of the "healed" tissues, since the formation, organisation, and biomechanical properties of the tissue are paramount to the function of the tissue and avoidance of additional procedures sue to re-tear.

\section{Compliance with Ethical Standards}

Conflict of interest The authors declare that they have no conflict of interest.

Open Access This article is distributed under the terms of the Creative Commons Attribution 4.0 International License (http:// creativecommons.org/licenses/by/4.0/), which permits unrestricted use, distribution, and reproduction in any medium, provided you give appropriate credit to the original author(s) and the source, provide a link to the Creative Commons license, and indicate if changes were made.

Publisher's Note Springer Nature remains neutral with regard to jurisdictional claims in published maps and institutional affiliations.

\section{References}

1. Prabhath A, Vernekar VN, Sanchez E, Laurencin CT. Growth factor delivery strategies for rotator cuff repair and regeneration. Int J Pharm. 2018;544:358-71. 
2. Caldwell JME, Zhang X, Lu HH, Levine WN. Biologic augmentation of rotator cuff repair. Elit Tech Shoulder Arthrose New Front Shoulder Preserv. 2015;4:193-210.

3. Gulotta LV, Rodeo SA. Growth factors for rotator cuff repair. Clin Sports Med. 2009;28:13-23.

4. Wildermann B, Klatte F. Biological aspects of rotator cuff healing. Muscles Ligaments Tendons J. 2011;1:160-7.

5. Rodeo SA, Potter HG, Kawamura S, Turner AS, Hyon JK, Atkinson BL. Biologic augmentation of rotator cuff tendonhealing with use of a mixture of osteoinductive growth factors. J Bone Jt Surg - Ser A. 2007;89:2485-97.

6. Pauly S, Klatte F, Strobel C, Schmidmaier G, Greiner S, Scheibel M, et al. BMP-2 and BMP-7 affect human rotator cuff tendon cells in vitro. J Shoulder Elb Surg. 2012;21:464-73.

7. Klatte-Schulz F, Pauly S, Scheibel M, Greiner S, Gerhardt C, Schmidmaier G, et al. Influence of age on the cell biological characteristics and the stimulation potential of male human tenocytelike cells. Eur Cells Mater. 2012;24:74-89.

8. Kabuto Y, Morihara T, Sukenari T, Kida Y, Oda R, Arai Y, et al. Stimulation of rotator cuff repair by sustained release of bone morphogenetic Protein-7 using a gelatin hydrogel sheet. Tissue Eng Part A. 2015;21:2025-33.

9. Lipner J, Shen H, Cavinatto L, Liu W, Havlioglu N, Xia Y, et al. In Vivo evaluation of adipose-derived stromal cells delivered with a nanofiber scaffold for tendon-to-bone repair. Tissue Eng Part A. 2015;21:2766-74.

10. Lee KW, Lee JS, Kim YS, Shim YB, Jang JW, Lee K II. Effective healing of chronic rotator cuff injury using recombinant bone morphogenetic protein-2 coated dermal patch in vivo. J Biomed Mater Res - Part B Appl Biomater. 2017;105:1840-6.

11. Randelli P, Randelli F, Ragone V, Menon A, D'Ambrosi R, Cucchi $\mathrm{D}$, et al. Regenerative medicine in rotator cuff injuries. BioMed Res Int. 2014;129515:1-9.

12. Mall NA, Tanaka MJ, Choi LS, Paletta GA. Factors affecting rotator cuff healing. J Bone Joint Surg Am. 2014;96:778-88.

13. Abtahi AM. Factors affecting healing after arthroscopic rotator cuff repair. World J Orthop. 2015;6:211.

14. McElvany MD, McGoldrick E, Gee AO, Neradilek MB, Matsen FA. Rotator cuff repair: published evidence on factors associated with repair integrity and clinical outcome. Am J Sports Med. 2015;43:491-500.

15. Liem D, Bartl C, Lichtenberg S, Magosch P, Habermeyer P. Clinical outcome and tendon integrity of arthroscopic versus mini-open supraspinatus tendon repair: a magnetic resonance imaging-controlled matched-pair analysis. Arthrosc - J Arthrosc Relat Surg. 2007;23:514-21.

16. Kasten P, Keil C, Grieser T, Raiss P, Streich N, Loew M. Prospective randomised comparison of arthroscopic versus miniopen rotator cuff repair of the supraspinatus tendon. Int Orthop. 2011;35:1663-70.

17. Buess E, Steuber KU, Waibl B. Open versus arthroscopic rotator cuff repair: a comparative view of 96 cases. Arthrosc - J Arthrosc Relat Surg. 2005;21:597-604.

18. Millar NL, Wu X, Tantau R, Silverstone E, Murrell GAC. Open versus two forms of arthroscopic rotator cuff repair. Clin Orthop Relat Res. 2009;467:966-78.

19. Nho SJ, Slabaugh MA, Seroyer ST, Grumet RC, Wilson JB, Verma NN, et al. Does the literature support double-row suture anchor fixation for arthroscopic rotator cuff repair? A systematic review comparing double-row and single-row suture anchor configuration. Arthrosc - J Arthrosc Relat Surg. 2009;25:1319-28.

20. Brown MJ, Pula DA, Kluczynski MA, Mashtare T, Bisson LJ. Does suture technique affect re-rupture in arthroscopic rotator cuff repair? A meta-analysis. Arthrosc - J Arthrosc Relat Surg. 2015;31:1576-82.
21. Sheean AJ, Hartzler RU, Burkhart SS. Rotator cuff repair: single row repair versus double row repair and Superior capsular reconstruction. Sports Med Arthrosc Rev. 2018;26:171-5.

22. Dehaan AM, Axelrad TW, Kaye E, Silvestri L, Puskas B, Foster TE. Does double-row rotator cuff repair improve functional outcome of patients compared with single-row technique? A systematic review. Am J Sports Med. 2012;40:1176-85.

23. Longo UG, Buchmann S, Berton A, Maffulli N, Denaro V. Arthroscopic knots and strength sutures for rotator cuff repair. Sports Med Arthrosc Rev. 2011;19:251-65.

24. McClellan WT, Schessler MJ, Ruch DS, Levin LS, Goldner RD. A knotless flexor tendon repair technique using a bidirectional barbed suture: an ex vivo comparison of three methods. Plast Reconstr Surg. 2011;128:322e-7e.

25. Fisher MB, Liang R, Jung H-J, Kim KE, Zamarra G, Almarza AJ, et al. Potential of healing a transected anterior cruciate ligament with genetically modified extracellular matrix bioscaffolds in a goat model. Knee Surgery, Sport Traumatol Arthrosc. 2012;20: 1357-65.

26. Cheung EV, Safran MR. Arthroscopic rotator cuff repairtraditional anchor techniques. Oper Tech Sports Med. 2012;20: 213-9.

27. Esquivel AO, Duncan DD, Dobrasevic N, Marsh SM, Lemos SE. Load to failure and stiffness: anchor placement and suture pattern effects on load to failure in rotator cuff repairs. Orthop J Sport Med. 2015;3:1-6.

28. Park MC, Cadet ER, Levine WN, Bigliani LU, Ahmad CS. Tendon-to-bone pressure distributions at a repaired rotator cuff footprint using transosseous suture and suture anchor fixation techniques. Am J Sports Med. 2005;33:1154-9.

29. Cadet ER, Hsu JW, Levine WN, Bigliani LU, Ahmad CS. The relationship between greater tuberosity osteopenia and the chronicity of rotator cuff tears. J Shoulder Elb Surg. 2008;17:73-7.

30. Jiang Y, Zhao J, van Holsbeeck MT, Flynn MJ, Ouyang X, Genant HK. Trabecular microstructure and surface changes in the greater tuberosity in rotator cuff tears. Skelet Radiol. 2002;31:522-8.

31. Shi LL, Edwards TB. The role of acromioplasty for management of rotator cuff problems: where is the evidence? Adv Orthop. 2012;2012:1-5.

32. Kukkonen J, Joukainen A, Lehtinen J, Mattila KT, Tuominen EKJ, Kauko T, et al. Treatment of nontraumatic rotator cuff tears: a randomized controlled trial with two years of clinical and imaging follow-up. J Bone Jt Surg - Am Vol. 2014;97:1729-37.

33. Cordasco FA, Backer M, Craig EV, Klein D, Warren RF. The partial-thickness rotator cuff tear: is acromioplasty without repair sufficient? Am J Sports Med. 2002;30:257-60.

34. MacDonald P, McRae S, Leiter J, Mascarenhas R, Lapner P. Arthroscopic rotator cuff repair with and without acromioplasty in the treatment of full-thickness rotator cuff tears: a multicenter, randomized controlled trial. J Bone Jt Surg - Ser A. 2011;93: 1953-60.

35. Krishnan L, Priddy LB, Esancy C, Klosterhoff BS, Stevens HY, Tran L, et al. Delivery vehicle effects on bone regeneration and heterotopic ossification induced by high dose BMP-2. Acta Biomater. 2017;49:101-12.

36. Pietrzak WS. Heterotopic ossification after the use of commercially available recombinant human bone morphogenetic proteins in four patients. J Craniofac Surg. 2009;20:1618-9.

37. Papanagiotou M, Dailiana ZH, Karachalios T, Varitimidis S, Hantes M, Dimakopoulos G, et al. Heterotopic ossification after the use of recombinant human bone morphogenetic protein-7. World J Orthop. 2017;8:36-41.

38. Kiss P. Results concerning products and sums of the terms of linear recurrences. Ann Math Inform 2000;27:1-7

39. Rothrauff BB, Pauyo T, Debski RE, Rodosky MW, Tuan RS, Musahl V. The rotator cuff organ: integrating developmental 
biology, tissue engineering, and surgical considerations to treat chronic massive rotator cuff tears. Tissue Eng Part B Rev. 2017;23:318-35.

40. Castricini R, Longo UG, De Benedetto M, Panfoli N, Pirani P, Zini $\mathrm{R}$, et al. Platelet-rich plasma augmentation for arthroscopic rotator cuff repair: a randomized controlled trial. Am J Sports Med. 2011;39:258-65.

41. Jo CH, Shin JS, Lee YG, Shin WH, Kim H, Lee SY, et al. Plateletrich plasma for arthroscopic repair of large to massive rotator cuff tears: a randomized, single-blind, parallel-group trial. Am J Sports Med. 2013;41:2240-8.

42. Beck J, Evans D, Tonino PM, Yong S, Callaci JJ. The biomechanical and histologic effects of platelet-rich plasma on rat rotator cuff repairs. Am J Sports Med. 2012;40:2037-44.

43. Filardo G, Matteo B Di, Kon E, Merli G, Marcacci M. Platelet-rich plasma in tendon-related disorders: results and indications. Knee Surg Sports Traumatol Arthrosc. 2018;26:1984-99.

44. Hernigou P, Flouzat Lachaniette CH, Delambre J, Zilber S, Duffiet $\mathrm{P}$, Chevallier N, et al. Biologic augmentation of rotator cuff repair with mesenchymal stem cells during arthroscopy improves healing and prevents further tears: a case-controlled study. Int Orthop. 2014;38:1811-8.

45. Yokoya S, Mochizuki Y, Natsu K, Omae H, Nagata Y, Ochi M. Rotator cuff regeneration using a bioabsorbable material with bone marrow-derived mesenchymal stem cells in a rabbit model. Am J Sports Med. 2012;40:1259-68.

46. Nixon AJ, Watts AE, Schnabel L V. Cell- and gene-based approaches to tendon regeneration. J Shoulder Elb Surg. 2012;21:278-94.

47. Mazzocca AD, McCarthy MBR, Chowaniec DM, Cote MP, Arciero RA, Drissi H. Rapid isolation of human stem cells (connective tissue progenitor cells) from the proximal humerus during arthroscopic rotator cuff surgery. Am J Sports Med. 2010;38: $1438-47$.

48. Killian ML, Cavinatto L, Galatz LM, Thomopoulos S. The role of mechanobiology in tendon healing. J Shoulder Elb Surg. 2012;21: 228-37.

49. De Ketelaere A, Vermeulen L, Vialard J, Van De Weyer I, Van Wauwe J, Haegeman G, et al. Involvement of GSK-3 $\beta$ in TWEAK-mediated NF-kB activation. FEBS Lett. 2004;566:60-4.

50. Galatz LM, Charlton N, Das R, Kim HM, Havlioglu N, Thomopoulos S. Complete removal of load is detrimental to rotator cuff healing. J Shoulder Elb Surg. 2009;18:669-75.

51. Kim YS, Chung SW, Kim JY, Ok JH, Park I, Oh JH. Is early passive motion exercise necessary after arthroscopic rotator cuff repair? Am J Sports Med. 2012;40:815-21.

52. Thigpen CA, Shaffer MA, Gaunt BW, Leggin BG, Williams GR, Wilcox RB. The American Society of Shoulder and Elbow Therapists' consensus statement on rehabilitation following arthroscopic rotator cuff repair. J Shoulder Elb Surg. 2016;25:521-35.

53. Gallagher BP, Bishop ME, Tjoumakaris FP, Freedman KB. Early versus delayed rehabilitation following arthroscopic rotator cuff repair: a systematic review. Phys Sportsmed. 2015;43:178-87.

54. Arndt J, Clavert P, Mielcarek P, Bouchaib J, Meyer N, Kempf JF. Immediate passive motion versus immobilization after endoscopic supraspinatus tendon repair: a prospective randomized study. Orthop Traumatol Surg Res. 2012;98:S131-8.

55. Hsu JE, Horneff JG, Gee AO. Immobilization after rotator cuff repair. What evidence do we have now? Orthop Clin North Am. 2016;47:169-77.

56. Shen C, Tang ZH, Hu JZ, Zou GY, Xiao RC, Yan DX. Does immobilization after arthroscopic rotator cuff repair increase tendon healing? A systematic review and meta-analysis. Arch Orthop Trauma Surg. 2014;134:1279-85

57. Plate JF, Brown PJ, Walters J, Clark JA, Smith TL, Freehill MT, et al. Advanced age diminishes tendon-to-bone healing in a rat model of rotator cuff repair. Am J Sports Med. 2014;42:859-68.
58. Gladstone JN, Bishop JY, Lo IKY, Flatow EL. Fatty infiltration and atrophy of the rotator cuff do not improve after rotator cuff repair and correlate with poor functional outcome. Am J Sports Med. 2007;35:719-28.

59. Melis B, Defranco MJ, Chuinard C, Walch G. Natural history of fatty infiltration and atrophy of the supraspinatus muscle in rotator cuff tears. Clin Orthop Relat Res. 2010;468:1498-505.

60. Kuzel BR, Grindel S, Papandrea R, Ziegler D. Fatty infiltration and rotator cuff atrophy. J Am Acad Orthop Surg. 2013;21: 613-23.

61. Meyer DC, Wieser K, Farshad M, Gerber C. Retraction of supraspinatus muscle and tendon as predictors of success of rotator cuff repair. Am J Sports Med. 2012;40:2242-7.

62. Fukuta S, Tsutsui T, Amari R, Wada K, Sairyo K. Tendon retraction with rotator cuff tear causes a decrease in cross-sectional area of the supraspinatus muscle on magnetic resonance imaging. J Shoulder Elb Surg. 2016;25:1069-75.

63. Chen X, Giambini H, Ben-Abraham E, An KN, Nassr A, Zhao C. Effect of bone mineral density on rotator cuff tear: an osteoporotic rabbit model. PLoS One. 2015;10:e139384.

64. Chung SW, Oh JH, Gong HS, Kim JY, Kim SH. Factors affecting rotator cuff healing after arthroscopic repair: osteoporosis as one of the independent risk factors. Am J Sports Med. 2011;39:2099-107.

65. Dougherty KA, Dilisio MF, Agrawal DK. Vitamin D and the immunomodulation of rotator cuff injury. J Inflamm Res. 2016;9:123-31.

66. Angeline ME, Ma R, Pascual-Garrido C, Voigt C, Deng XH, Warren RF, et al. Effect of diet-induced vitamin d deficiency on rotator cuff healing in a rat model. Am J Sports Med. 2014;42: 27-34.

67. Cohen DB, Kawamura S, Ehteshami JR, Rodeo SA. Indomethacin and celecoxib impair rotator cuff tendon-to-bone healing. Am J Sports Med. 2006;34:362-9.

68. Forslund C, Bylander B, Aspenberg P. Indomethacin and celecoxib improve tendon healing in rats. Acta Orthop Scand. 2003;74:465-9.

69. Dimmen S, Engebretsen L, Nordsletten L, Madsen JE. Negative effects of parecoxib and indomethacin on tendon healing: an experimental study in rats. Knee Surgery, Sport Traumatol Arthrosc. 2009;17:835-9.

70. Hadzic A, Williams BA, Karaca PE, Hobeika P, Unis G, Dermksian J, et al. For outpatient rotator cuff surgery, nerve block anesthesia provides superior same-day recovery over general anesthesia. Anesthesiology. 2005;102:1001-7.

71. Tetzlaff JE, Brems J, Dilger J. Intraarticular morphine and bupivacaine reduces postoperative pain after rotator cuff repair. Reg Anesth Pain Med. 2000;25:611-4.

72. Jo CH, Shin JS, Huh J. Multimodal analgesia for arthroscopic rotator cuff repair: a randomized, placebo-controlled, doubleblind trial. Eur J Orthop Surg Traumatol. 2014;24:315-22.

73. Bedi A, Fox AJS, Harris PE, Deng XH, Ying L, Warren RF, et al. Diabetes mellitus impairs tendon-bone healing after rotator cuff repair. J Shoulder Elb Surg. 2010;19:978-88.

74. Cho NS, Moon SC, Jeon JW, Rhee YG. The influence of diabetes mellitus on clinical and structural outcomes after arthroscopic rotator cuff repair. Am J Sports Med. 2015;43:991-7.

75. Chen AL, Shapiro JA, Ahn AK, Zuckerman JD, Cuomo F. Rotator cuff repair in patients with type I diabetes mellitus. J Shoulder Elb Surg. 2003;12:416-21.

76. Clement ND, Hallett A, MacDonald D, Howie C, McBirnie J. Does diabetes affect outcome after arthroscopic repair of the rotator cuff? J Bone Jt Surg - Br. 2010;92-B:1112-7.

77. Carbone S, Gumina S, Arceri V, Campagna V, Fagnani C, Postacchini F. The impact of preoperative smoking habit on rotator cuff tear: cigarette smoking influences rotator cuff tear sizes. J Shoulder Elb Surg. 2012;21:56-60. 
78. Baumgarten KM, Gerlach D, Galatz LM, Teefey SA, Middleton WD, Ditsios K, et al. Cigarette smoking increases the risk for rotator cuff tears. Clin Orthop Relat Res. 2010;468:1534-41.

79. Mallon WJ, Misamore G, Snead DS, Denton P. The impact of preoperative smoking habits on the results of rotator cuff repair. J Shoulder Elb Surg. 2004;13:129-32.

80. Beason DP, Abboud JA, Kuntz AF, Bassora R, Soslowsky LJ. Cumulative effects of hypercholesterolemia on tendon biomechanics in a mouse model. J Orthop Res. 2011;29:380-3.

81. Beason DP, Tucker JJ, Lee CS, Edelstein L, Abboud JA, Soslowsky LJ. Rat rotator cuff tendon-to-bone healing properties are adversely affected by hypercholesterolemia. J Shoulder Elb Surg. 2014;23:867-72.

82. Beason DP, Hsu JE, Marshall SM, McDaniel AL, Temel RE, Abboud JA, et al. Hypercholesterolemia increases supraspinatus tendon stiffness and elastic modulus across multiple species. J Shoulder Elb Surg. 2013;22:681-6.

83. Abboud JA, Kim JS. The effect of hypercholesterolemia on rotator cuff disease. Clin Orthop Relat Res. 2010;468:1493-7

84. Chung SW, Park H, Kwon J, Choe GY, Kim SH, Oh JH. Effect of hypercholesterolemia on fatty infiltration and quality of tendon-tobone healing in a rabbit model of a chronic rotator cuff tear: electrophysiological, biomechanical, and histological analyses. Am J Sports Med. 2015;44:1153-64.

85. Neugebauer JM, Kwon S, Kim H-S, Donley N, Tilak A, Sopory S, et al. The prodomain of BMP4 is necessary and sufficient to generate stable BMP4/7 heterodimers with enhanced bioactivity in vivo. Proc Natl Acad Sci. 2015;112:E2307-16.

86. Kovacevic D, Rodeo SA. Biological augmentation of rotator cuff tendon repair. Clin Orthop Relat Res. 2008;466:622-33.

87. Provencher MT, Mazzocca A, Romeo AA. Biologics in rotator cuff surgery: management of rotator cuff tears with an extracellular matrix patch. Tech Orthop. 2007;22:43-54.

88. Barretti P. Evidence-based medicine: an update on treatments for peritoneal dialysis-related peritonitis. World J Nephrol. 2015;4: 287-94.

89. Cole BJ, Gomoll AH, Yanke A, Pylawka T, Lewis P, MacGillivray JD, et al. Biocompatibility of a polymer patch for rotator cuff repair. Knee Surgery, Sport Traumatol Arthrosc. 2007;15:632-7.

90. Arzeno A, Wang T, Huddleston JI. Abundant heterotopic bone formation following use of rhBMP-2 in the treatment of acetabular bone defects during revision hip arthroplasty. Arthroplast Today. 2018;4:162-8.

91. Shi L, Sun W, Gao F, Cheng L, Li Z. Heterotopic ossification related to the use of recombinant human BMP-2 in osteonecrosis of femoral head. Med (United States). 2017;96:e7413.

92. Hettrich CM, Beamer BS, Bedi A, Deland K, Deng XH, Ying L, et al. The effect of rhPTH on the healing of tendon to bone in a rat model. J Orthop Res. 2012;30:769-74.

93. Duchman KR, Goetz JE, Uribe BU, Amendola AM, Barber JA, Malandra AE, et al. Delayed administration of recombinant human parathyroid hormone improves early biomechanical strength in a rat rotator cuff repair model. J Shoulder Elb Surg. 2016;25: 1280-7.

94. Coleman SH, Fealy S, Ehteshami JR, MacGillivray JD, Altchek DW, Warren RF, et al. Chronic rotator cuff injury and repair model in sheep. J Bone Jt Surg - Ser A. 2003;85:2391-402.

95. Seeherman HJ, Archambault JM, Rodeo SA, Turner AS, Zekas L, D'Augusta D, et al. rhBMP-12 accelerates healing of rotator cuff repairs in a sheep model. J Bone Jt Surg - Ser A. 2008;90: 2206-19.

96. Novakova SS, Mahalingam VD, Florida SE, Mendias CL, Allen A, Arruda EM, et al. Tissue-engineered tendon constructs for rotator cuff repair in sheep. J Orthop Res. 2018;36:289-99.

97. Harryman DT, Mack LA, Wang KY, Jackins SE, Richardson ML, Matsen FA. Repairs of the rotator cuff. Correlation of functional results with integrity of the cuff. J Bone Jt Surg - Ser A. 1991;73: 982-9.

98. Lebaschi AH, Deng XH, Camp CL, Zong J, Cong GT, Carballo $\mathrm{CB}$, et al. Biomechanical, histologic, and molecular evaluation of tendon healing in a new murine model of rotator cuff repair. Arthrosc - J Arthrosc Relat Surg. 2018;34:1173-83.

99. Nakajima A, Shimoji N, Shiomi K, Shimizu S, Moriya H, Einhorn TA, et al. Mechanisms for the enhancement of fracture healing in rats treated with intermittent low-dose human parathyroid hormone (1-34). J Bone Miner Res. 2002;17:2038-47.

100. Tsai AD, Yeh LCC, Lee JC. Effects of osteogenic protein-1 (OP-1, BMP-7) on gene expression in cultured medial collateral ligament cells. J Cell Biochem. 2003;90:777-91.

101. Nicklin S, Morris H, Yu Y, Harrison J, Walsh WR. OP-1 augmentation of tendon-bone healing in an ovine ACL reconstruction. Trans Orthop Res Soc. 2000;25:155.

102. Yeh LCC, Tsai AD, Lee JC. Bone morphogenetic protein-7 regulates differentially the mRNA expression of bone morphogenetic proteins and their receptors in rat Achilles and patellar tendon cell cultures. J Cell Biochem. 2008;104:2107-22.

103. Ranly DM, McMillan J, Keller T, Lohmann CH, Meunch T, Cochran DL, et al. Platelet-derived growth factor inhibits demineralized bone matrix-induced intramuscular cartilage and bone formation: a study of immunocompromised mice. J Bone Jt Surg - Ser A. 2005;87:2052-64.

104. Davies OG, Grover LM, Lewis MP, Liu Y. PDGF is a potent initiator of bone formation in a tissue engineered model of pathological ossification. J Tissue Eng Regen Med. 2018;12:e355-67.

105. Graham S, Leonidou A, Lester M, Heliotis M, Mantalaris A, Tsiridis E. Investigating the role of PDGF as a potential drug therapy in bone formation and fracture healing. Expert Opin Investig Drugs. 2009;18:1633-54.

106. Al-Zube L, Breitbart EA, O'Connor JP, Parsons JR, Bradica G, Hart CE, et al. Recombinant human platelet-derived growth factor $\mathrm{BB}$ (rhPDGF-BB) and beta-tricalcium phosphate/collagen matrix enhance fracture healing in a diabetic rat model. J Orthop Res. 2009;27:1074-81.

107. Einhorn TA, Gerstenfeld LC. Fracture healing: mechanisms and interventions. Nat Rev Rheumatol. 2015;11:45-54.

108. Caplan AI, Correa D. PDGF in bone formation and regeneration: new insights into a novel mechanism involving MSCs. J Orthop Res. 2011;29:1795-803.

109. Sakiyama-Elbert SE, Das R, Gelberman RH, Harwood F, Amiel $\mathrm{D}$, Thomopoulos S. Controlled-release kinetics and biologic activity of platelet-derived growth factor-BB for use in flexor tendon repair. J Hand Surg Am. 2008;33:1548-57.

110. Docheva D, Müller SA, Majewski M, Evans CH. Biologics for tendon repair. Adv Drug Deliv Rev. 2015;84:222-39.

111. Yang G, Rothrauff BB, Tuan RS. Tendon and ligament regeneration and repair: clinical relevance and developmental paradigm. Birth Defects Res C Embryo Today. 2013;99:203-22.

112. Schmid GJ, Kobayashi C, Sandell LJ, Ornitz DM. Fibroblast growth factor expression during skeletal fracture healing in mice. Dev Dyn. 2009;238:766-74.

113. Tokunaga T, Karasugi T, Arimura H, Yonemitsu R, Sakamoto H, Ide J, et al. Enhancement of rotator cuff tendon-bone healing with fibroblast growth factor 2 impregnated in gelatin hydrogel sheets in a rabbit model. J Shoulder Elb Surg. 2017;26:1708-17.

114. Kim HM, Galatz LM, Das R, Havlioglu N, Rothermich SY, Thomopoulos S. The role of transforming growth factor beta isoforms in tendon-to-bone healing. Connect Tissue Res. 2011;52: 87-98.

115. Manning CN, Kim HM, Sakiyama-Elbert S, Galatz LM, Havlioglu N, Thomopoulos S. Sustained delivery of transforming growth factor beta three enhances tendon-to-bone healing in a rat model. J Orthop Res. 2011;29:1099-105. 
116. Kovacevic D, Fox AJ, Bedi A, Ying L, Deng XH, Warren RF, et al. Calcium-phosphate matrix with or without TGF- $\beta 3$ improves tendon-bone healing after rotator cuff repair. Am J Sports Med. 2011;39:811-9.
117. Al-Bluwi MT, Azam MQ, Sadat-Ali M. The effect of bone growth factor in the tendon to bone healing in anterior cruciate ligament reconstruction: an experimental study in rabbits. Int J Appl Basic Med Res Wolters Kluwer - Medknow Publications. 2016;6:23-7. 